\title{
PIXE and ToF-SIMS analysis of streaker samplers filters
}

\author{
A. D'Alessandro ${ }^{\text {a, }}$ S. Nava ${ }^{\text {a }}$, R. Van Ham ${ }^{\text {b }}$, A. Adriaens ${ }^{\text {c }, ~ F . ~ L u c a r e l l i ~}{ }^{\text {d, }}$, \\ G. Marcazzan ${ }^{\text {e }}$, P. Prati ${ }^{\text {a,*}}$, G. Valli ${ }^{\text {e }}$, R. Vecchi ${ }^{\text {e }}$, A. Zucchiatti ${ }^{\text {a }}$ \\ a Dipartimento di Fisica and INFN, Università di Genova, Via Dodecaneso 33, 16146 Genova, Italy \\ ${ }^{\mathrm{b}}$ Department of Chemistry, University of Antwerp, Universiteitsplein 1, B-2610 Antwerp, Belgium \\ ${ }^{\mathrm{c}}$ Department of Analytical Chemistry, Ghent University, Krijgslaan 281 - S12, B-9000 Ghent, Belgium \\ d Dipartimento di Fisica and INFN, Università di Firenze, Largo E. Fermi 2, 50125 Firenze, Italy \\ ${ }^{\mathrm{e}}$ Istituto di Fisica Generale Applicata and INFN, Università di Milano, Via Celoria 16, 20133 Milano, Italy
}

Received 29 July 2003; received in revised form 9 February 2004

\begin{abstract}
The paper presents methodological innovations introduced in the characterisation of urban aerosol collected in Italy in a recent campaign. Two complementary ion beam analysis (IBA) techniques were used to analyse Nuclepore filters used in continuous streaker samplers to collect airborn particles in four Italian towns. $\mathrm{Na}$ to $\mathrm{Pb}$ elemental concentrations were obtained by particle induced X-ray emission (PIXE), while time of flight secondary ion mass spectrometry (ToF-SIMS) produced, on the same samples, time trends for several elements and molecular fragments. In addition, light attenuation measurements were used as a tracer for black carbon. The data produced by these three techniques was merged into a unique data set to address the characterisation of particulate matter sources. Correlations between elemental concentration trends (PIXE) and relative trends for molecular fragments (ToF-SIMS) and black carbon (light attenuation) have been studied by cluster and principal component analysis.
\end{abstract}

(c) 2004 Elsevier B.V. All rights reserved.

PACS: $07.88 ; 82.70 . \mathrm{K}$

Keywords: Particulate matter; PIXE; ToF-SIMS; Streaker sampler; Urban pollution

\section{Introduction}

Ion beam analysis (IBA) has in the last years become a relatively common approach for analysing the elemental composition of particulate matter. The latter has been stimulated by the

\footnotetext{
${ }^{*}$ Corresponding author. Tel.: +39-0103536439; fax: +39010314218.

E-mail address: prati@ge.infn.it (P. Prati).
}

successful use of methods, such as particle induced X-ray analysis (PIXE) [1], particle induced gamma-ray emission (PIGE) [2] and Rutherford backscattering spectrometry (RBS) [3] in aerosol studies. Nuclepore and other polycarbonate filters are frequently used as substrates for particulate sampling, even though they can present, due to their composition, severe background problems in the detection of light elements (e.g. H, N, O, C, B). Using two-stage streaker samplers (PIXE International Corporation, Tallahassee) it is possible to 
collect fine aerosol particles on Nuclepore filters continuously for a period variable between a few hours and some weeks. In urban aerosol sampling, a hourly resolution may be adopted corresponding to the use of one filter for 7 days continuous sampling [4]. The advantage of using these types of streaker samplers is that measurements with PIXE can be performed scanning the beam automatically over the multi-hours samples and in a relatively short time: actually the streaker sampler has been originally designed [4] for IBA applications. On the other side, this particular type of filters requires non-destructive analytical techniques, since the time sequence of particulate deposition forms a continuous "streak" where $1 \mathrm{~mm}$ corresponds to a few hours of sampling. Some widely used analytical techniques, such as inductively coupled plasma mass spectrometry (ICP-MS), are difficult to be applied in this case since they would require to cut the filters in about 170 thin slices ( $1 \mathrm{~mm}$ wide), thus loosing the advantages offered by streaker samplers.

Investigations, as described above, usually aim at elemental analysis. The study of correlations between elemental concentration time series contributes in identification of particulate matter sources [5]. Other methods must be used when one wants to obtain chemical speciation. In view of this aspect, a recent and exploratory work was undertaken in which time-of-flight secondary ion mass spectrometry (ToF-SIMS) in static mode was used as a complementary tool to PIXE in the analysis of Nuclepore streaker filters [6]. In that study, a method was developed to analyse streaker samples by ToF-SIMS in their entirety without the need of cutting the filter. Simultaneous detection of surface-specific information such as low $Z$ elemental ions $(Z<11)$ together with mean $Z$ elemental ions $(11 \leqslant Z<82)$ and molecular fragment ions (e.g. $\mathrm{SO}_{4}^{-}, \mathrm{NO}_{3}^{-}, \mathrm{NH}_{4}^{+}$) were shown to be feasible. In addition, static SIMS seemed also suitable for observing secondary chemistry going on at the surface of particles as the technique analyses the top monolayer of the sample. In that preliminary phase, the comparison between PIXE and ToFSIMS was not carried on the same samples but it was simply observed that the two techniques gave reasonable results on similar samples [6].
The present study discusses the combined use of PIXE and ToF-SIMS in the frame of a coordinated study to characterise particulate matter in four major Italian towns [7]. Both analysis methods have been used on the same samples, namely four streaker filters exposed during the same days in the four towns. This setup gave us the opportunity to compare elemental concentrations trends deduced for the same elements by both techniques (in arbitrary units in the case of ToF-SIMS) and to merge all the results in a unique data base for successive statistical analysis. Prior to the PIXE and ToF-SIMS measurements, the samples were scanned optically [8]. The latter gives an estimate of the black carbon concentration trend [7], thus completing the analytical tools utilized in this work.

\section{Material and methods}

All the samples used for the present study were collected during a coordinated campaign in four major Italian towns [7]. In each town a two-stage streaker sampler was installed and a weekly sampling started on January 18th 2001.

Full details of the samplers, their cut-off diameters and their control units can be found elsewhere [9]. Briefly, in a streaker sampler, particles are separated on different stages: an impactor deposits the aerosol coarse fraction $(2.5 \mu \mathrm{m}<$ $\left.D_{\mathrm{ae}}<10 \mu \mathrm{m}\right)$ on a Kapton foil while the fine fraction $\left(D_{\mathrm{ae}}<2.5 \mu \mathrm{m}\right)$ is collected on a Nuclepore filter having $0.4 \mu \mathrm{m}$ pores. Sampling flux is $1 \mathrm{l} / \mathrm{min}$. The two collecting plates (Kapton and Nuclepore) are paired on a cartridge which rotates at constant speed for a week: this produces a circular continuous deposition of particular matter ("streak") on both stages. In this work we have analysed the fine fraction only.

Black carbon trends were obtained with a simple optical method described in [8]. Briefly, if the composition of the deposit (e.g. the particulate matter accumulated on a filter) is constant, the light absorption will depend exponentially on the deposit thickness: $I=I_{0} \mathrm{e}^{-\mu x}$ [10]. The absorption coefficient $\mu$ is determined primarily by the aerosol black carbon content and to a minor extent by the 
rest of the aerosol [11]. The quantity $\ln \left(I_{0} / I\right)$, measured with an hourly resolution along the streaks, describes with good approximation the time behaviour of black carbon and roughly, if its concentration in the aerosol is not varying so much, the total particulate matter. In the following we use the acronym "OPT" for the quantity $\ln \left(I_{0} / I\right)$.

The elemental composition of the streaker deposits was then measured by the PIXE external beam facility in Florence, based on a Van de Graaff accelerator: this facility has been used several times in the past for aerosol studies and it is extensively described in [12]. For this experiment the beam (3 $\mathrm{MeV}$ protons) was focussed in a rectangular spot (width: $1 \mathrm{~mm}$, height: $3 \mathrm{~mm}$ ) and it was moved along the streak in steps corresponding to $1 \mathrm{~h}$ of aerosol sampling. Each step took 5 min of beam time, which means that scanning the whole streaker required about $15 \mathrm{~h}$ with, on average, $3 \mu \mathrm{C}$ collected per step.

The elemental thickness was obtained by comparing the streaker yields with a sensitivity curve [counts $\mu \mathrm{C}^{-1} \mu \mathrm{g}^{-1} \mathrm{~cm}^{2}$ ] measured in the same geometry on a set of thin standards certified within 5\% (Micromatter Inc.). All X-ray spectra have been fitted for 24 elements $(\mathrm{Na}, \mathrm{Mg}, \mathrm{Al}, \mathrm{Si}, \mathrm{P}, \mathrm{S}$, $\mathrm{Cl}, \mathrm{K}, \mathrm{Ca}, \mathrm{Ti}, \mathrm{V}, \mathrm{Cr}, \mathrm{Mn}, \mathrm{Fe}, \mathrm{Co}, \mathrm{Ni}, \mathrm{Cu}, \mathrm{Zn}, \mathrm{As}$, $\mathrm{Se}, \mathrm{Br}, \mathrm{Sr}, \mathrm{Zr}, \mathrm{Pb}$ ) using the GUPIX software package [13].

Several molecular fragments and elements have in addition been measured by ToF-SIMS at the facility of the University of Antwerp following the approach described in [6]. Briefly, a focussed $\mathrm{Ga}^{+}$ ion beam was rastered over an area of $300 \times 300$ $\mu \mathrm{m}^{2}$ with a primary ion current of approximately $0.2 \mathrm{pA}$ for $5 \mathrm{~min}$. Using a pulsed low energy electron flood gun $(\approx 18 \mathrm{eV})$ for charge compensation [6,14], the mass resolution $(m / \Delta m)$ obtained on this insulating substrate is $\sim 1700$ for $\mathrm{H}^{+}$and $\sim 1400$ for $\mathrm{H}^{-}$. This mass resolution is sufficient to distinguish between inorganic $(\mathrm{m} / \mathrm{z}$ under nominal mass) and organic compounds $(\mathrm{m} / \mathrm{z}$ above nominal mass). The background in the spectra is a factor 10 higher with the use of electrons for charge compensation in comparison to spectra taken on conducting substrates. The primary ion dose was kept below the static limit of $10^{14}$ ions/ $\mathrm{cm}^{2}$. The secondary ion intensities were collected in both the negative and the positive mode for 50 points $\left(\right.$ size $\left.=300 \times 300 \mu^{2}\right)$ on each filter, approximately equally spaced. This corresponded with one analysis point (about 15 min of particulate matter deposition time) for each $3.4 \mathrm{~h}$ of sampling. The time needed for the analysis in one mode took about $250 \mathrm{~min}$. At each new sampling point the reflector voltage had to be adjusted for optimal mass resolution. Taking into account these conditions, we were able to measure one mode every day. To interpret the data, each peak area had to be calculated summing the counts in the peak region and subtracting the continuum background underneath, due to the irregular peak shape induced by residual surface charge on insulating samples.

\section{Results}

The PIXE results, i.e. concentration time series for each detected element and statistical analysis to identify the particulate matter sources, together with the information deduced by the optical analysis of Nuclepore streaker frames are fully described elsewhere [7]. For the ToF-SIMS results we selected a relevant set of mass peaks to compare with PIXE, i.e. $\mathrm{Na}, \mathrm{Al}, \mathrm{K}, \mathrm{Fe}, \mathrm{Cu}, \mathrm{Pb}$ and $\mathrm{NH}_{x}$ in the positive mode spectra and $\mathrm{NO}_{x}$, $\mathrm{SO}_{x}, \mathrm{HS}, \mathrm{HSO}_{x}, \mathrm{NaSO}_{x}$ and $\mathrm{Br}$ signals in negative mode spectra. It may be useful to mention here that ToF-SIMS spectra tend to be very complicated, resulting in only a minor fraction of the peaks that can be positively identified. In particular, many organic fragments could be detected, which have been excluded from the analysis since it is very difficult to link them to a specific molecule or molecule fragment. Moreover, many of the element/fragment signals were weak and it was difficult to distinguish them from the background as the support is a polycarbonate filter, which is a source itself of interfering organic fragments. We have only considered for analysis charged fragments and/or molecules which signals were at two sigma level over the background measured with a clean Nuclepore substrata. 
Our first goal was to check whether or not the time series obtained by ToF-SIMS could be merged with the PIXE data into a unique set. We therefore selected elements detected by both techniques and we compared their time trends. In Fig. 1 we report the data for $\mathrm{Fe}$, which is one of the most abundant elements in particulate matter. Although the data time spacing is not the same ( $1 \mathrm{~h}$ for PIXE and about $3.4 \mathrm{~h}$ for ToF-SIMS) in all the four towns both the techniques gave similar trends for Fe concentration. In some cases (see Fig. 1) the lower time resolution of ToF-SIMS data does not allow the detection of fast and short Fe concentration changes. In other cases, the dis- agreement between the two techniques could be attributed to the relatively small analysis areas and to the smaller thickness analysed (a few monolayer for particulate matter) by ToF-SIMS, both the characteristics resulting in larger statistical fluctuations. The same picture was observed for the other elemental species measured by both the techniques.

To quantitatively compare the two techniques we put together all the data extracting from PIXE set a value each $3.4 \mathrm{~h}$. The Pearson correlation coefficient between these reduced PIXE sets and ToF-SIMS data are reported in Table 1 for some elemental fragments detected by SIMS in positive
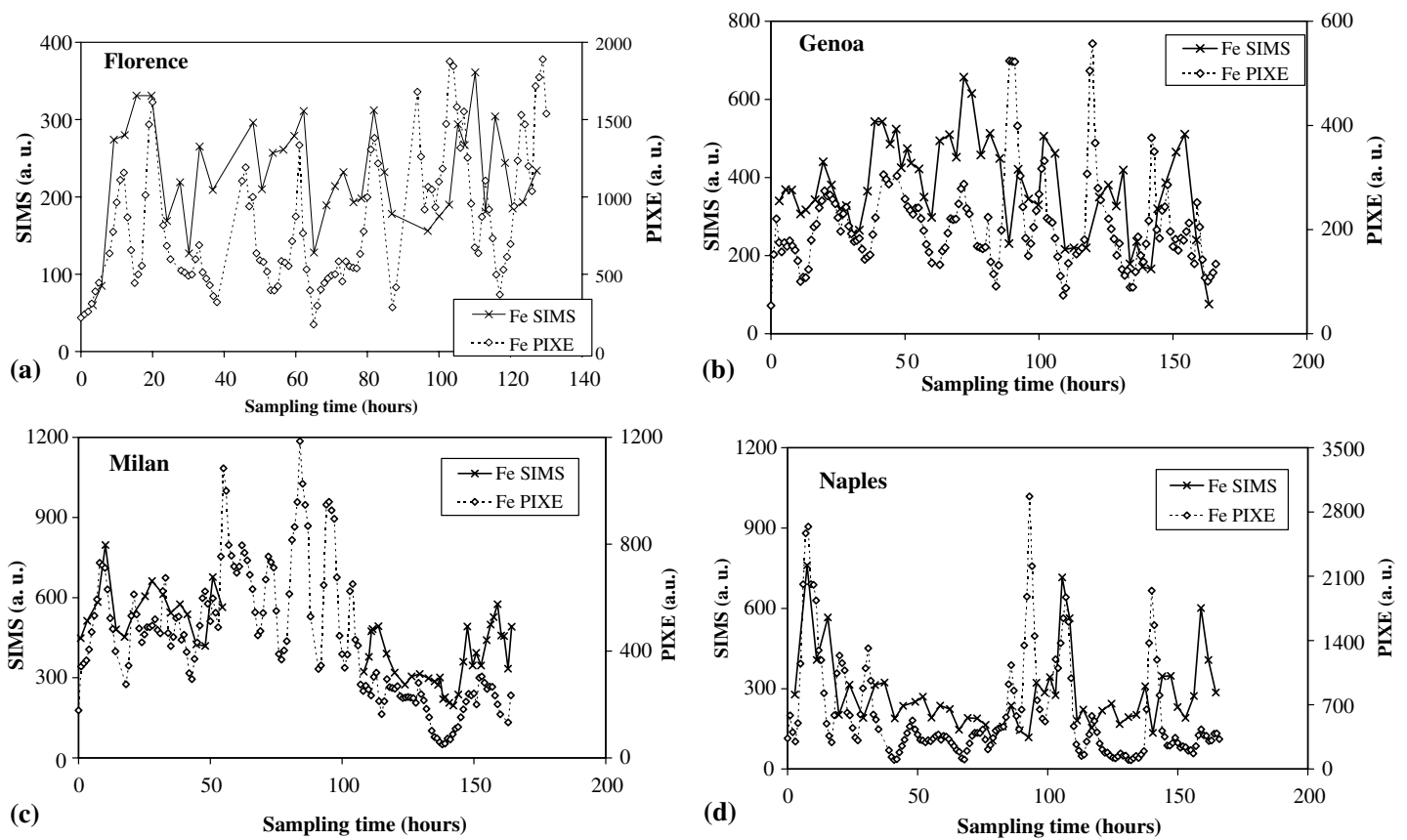

Fig. 1. Iron concentration time series, in arbitrary units, obtained by PIXE (dotted) and ToF-SIMS (full line) analyses on the Nuclepore streaker frames of Florence (a), Genoa (b), Milan (c) and Naples (d). The central portion of the filter esposed in Milan had been damaged and could be analysed by PIXE only. Hour 0 marks the sampling start (January 17th, 2001, 11 a.m.).

Table 1

Pearson correlation coefficient between PIXE and ToF-SIMS (positive mode) time series for elemental $\mathrm{K}, \mathrm{Fe}$ and $\mathrm{Cu}$

\begin{tabular}{lllll}
\hline Element & Florence & Genoa & Milan & Naples \\
\hline $\mathrm{K}$ & 0.73 & 0.50 & 0.64 & 0.80 \\
$\mathrm{Fe}$ & 0.66 & 0.50 & 0.79 & 0.63 \\
$\mathrm{Cu}$ & 0.54 & 0.50 & 0.74 & 0.50 \\
\hline
\end{tabular}


Table 2

Factors composition obtained by PCA, after VARIMAX rotation, for the data sets of Florence (Panel A), Genoa (Panel B), Milan (Panel C) and Naples (Panel D)

\begin{tabular}{|c|c|c|c|c|}
\hline & Factor 1 & Factor 2 & Factor 3 & Factor 4 \\
\hline \multicolumn{5}{|c|}{ Panel A: PCA-Florence } \\
\hline NO & 0.57 & 0.57 & 0.25 & 0.39 \\
\hline S-SIMS & 0.36 & 0.13 & 0.83 & 0.12 \\
\hline HS & 0.23 & 0.09 & 0.91 & 0.00 \\
\hline $\mathrm{NO}_{2}$ & 0.01 & 0.93 & 0.29 & 0.05 \\
\hline SO & 0.33 & 0.37 & 0.79 & -0.01 \\
\hline $\mathrm{NO}_{3}$ & 0.12 & 0.93 & 0.24 & 0.07 \\
\hline $\mathrm{SO}_{2}$ & 0.37 & 0.72 & 0.47 & -0.16 \\
\hline Br-SIMS & -0.05 & 0.73 & 0.02 & -0.52 \\
\hline $\mathrm{SO}_{3}$ & -0.10 & 0.35 & 0.83 & -0.17 \\
\hline $\mathrm{SO}_{4}$ & 0.90 & 0.20 & 0.27 & 0.02 \\
\hline $\mathrm{HSO}_{4}$ & 0.94 & 0.12 & 0.24 & 0.11 \\
\hline $\mathrm{NaSO}_{4}$ & 0.18 & -0.34 & 0.01 & 0.75 \\
\hline OPT & -0.77 & -0.04 & -0.11 & -0.58 \\
\hline Al-PIXE & -0.74 & 0.13 & -0.15 & -0.47 \\
\hline S-PIXE & -0.31 & -0.29 & 0.23 & -0.75 \\
\hline Pb-PIXE & -0.73 & -0.08 & -0.09 & -0.62 \\
\hline$\%$ variance & 27 & 23 & 22 & 16 \\
\hline \multicolumn{5}{|c|}{ Panel B: PCA - Genoa } \\
\hline $\mathrm{NO}$ & 0.00 & 0.26 & -0.74 & -0.01 \\
\hline S-SIMS & -0.03 & 0.87 & 0.16 & 0.08 \\
\hline HS & 0.02 & 0.86 & 0.13 & 0.22 \\
\hline $\mathrm{NO}_{2}$ & 0.72 & 0.39 & -0.43 & 0.13 \\
\hline SO & 0.18 & 0.85 & -0.28 & -0.06 \\
\hline $\mathrm{NO}_{3}$ & 0.70 & 0.36 & -0.43 & 0.15 \\
\hline $\mathrm{SO}_{2}$ & 0.47 & 0.76 & -0.26 & 0.06 \\
\hline Br-SIMS & 0.68 & 0.25 & -0.15 & -0.33 \\
\hline $\mathrm{SO}_{3}$ & 0.39 & 0.83 & -0.23 & 0.00 \\
\hline $\mathrm{SO}_{4}$ & -0.53 & 0.53 & -0.15 & -0.33 \\
\hline $\mathrm{HSO}_{4}$ & -0.85 & 0.00 & 0.03 & -0.34 \\
\hline $\mathrm{NaSO}_{4}$ & -0.63 & -0.09 & 0.36 & -0.21 \\
\hline OPT & 0.93 & 0.03 & 0.04 & 0.08 \\
\hline Na-PIXE & 0.35 & 0.02 & 0.56 & 0.59 \\
\hline Al-PIXE & 0.01 & 0.17 & -0.16 & 0.77 \\
\hline S-PIXE & -0.21 & 0.13 & 0.69 & -0.08 \\
\hline Pb-PIXE & 0.80 & 0.12 & 0.12 & -0.17 \\
\hline$\%$ variance & 29 & 25 & 13 & 9 \\
\hline \multicolumn{5}{|c|}{ Panel C: PCA-Milan } \\
\hline NO & 0.23 & 0.63 & -0.11 & 0.51 \\
\hline S-SIMS & 0.85 & -0.17 & -0.15 & 0.19 \\
\hline HS & 0.81 & -0.17 & 0.17 & 0.16 \\
\hline $\mathrm{NO}_{2}$ & -0.07 & 0.89 & 0.24 & -0.20 \\
\hline $\mathrm{SO}$ & 0.85 & 0.07 & -0.29 & 0.04 \\
\hline $\mathrm{NO}_{3}$ & 0.10 & 0.93 & 0.06 & -0.27 \\
\hline $\mathrm{SO}_{2}$ & 0.84 & 0.38 & -0.13 & -0.08 \\
\hline Br-SIMS & -0.02 & 0.03 & 0.78 & -0.21 \\
\hline $\mathrm{SO}_{3}$ & 0.78 & 0.56 & -0.01 & -0.03 \\
\hline $\mathrm{SO}_{4}$ & 0.86 & 0.26 & -0.27 & -0.07 \\
\hline $\mathrm{HSO}_{4}$ & 0.88 & 0.03 & -0.27 & $\begin{array}{l}0.04 \\
\text { (continued on next page) }\end{array}$ \\
\hline
\end{tabular}


Table 2 (continued)

\begin{tabular}{|c|c|c|c|c|}
\hline & Factor 1 & Factor 2 & Factor 3 & Factor 4 \\
\hline $\mathrm{NaSO}_{4}$ & 0.06 & -0.27 & 0.10 & 0.80 \\
\hline OPT & -0.26 & 0.61 & 0.46 & -0.21 \\
\hline Al-PIXE & -0.14 & 0.05 & 0.70 & 0.20 \\
\hline S-PIXE & -0.09 & 0.13 & 0.88 & 0.19 \\
\hline Mn-PIXE & 0.36 & 0.69 & 0.14 & 0.13 \\
\hline Br-PIXE & -0.31 & 0.20 & 0.80 & -0.08 \\
\hline$\%$ variance & 31 & 21 & 18 & 8 \\
\hline \multicolumn{5}{|c|}{ Panel D: PCA - Naples } \\
\hline NO & 0.78 & 0.34 & 0.10 & -0.30 \\
\hline S-SIMS & 0.90 & -0.22 & 0.20 & -0.13 \\
\hline HS & 0.92 & -0.16 & 0.23 & -0.10 \\
\hline $\mathrm{NO}_{2}$ & -0.19 & 0.83 & -0.28 & 0.07 \\
\hline $\mathrm{SO}$ & 0.66 & 0.14 & 0.59 & -0.10 \\
\hline $\mathrm{NO}_{3}$ & -0.16 & 0.84 & -0.23 & 0.02 \\
\hline $\mathrm{SO}_{2}$ & 0.30 & 0.82 & 0.22 & -0.02 \\
\hline Br-SIMS & -0.33 & 0.68 & -0.09 & 0.29 \\
\hline $\mathrm{SO}_{3}$ & -0.11 & 0.87 & 0.24 & 0.19 \\
\hline $\mathrm{SO}_{4}$ & 0.43 & -0.19 & 0.81 & 0.13 \\
\hline $\mathrm{HSO}_{4}$ & 0.50 & -0.22 & 0.77 & 0.11 \\
\hline $\mathrm{NaSO}_{4}$ & 0.69 & -0.13 & 0.06 & -0.13 \\
\hline OPT & -0.47 & 0.37 & -0.45 & 0.58 \\
\hline Na-PIXE & 0.77 & -0.26 & -0.16 & 0.33 \\
\hline Al-PIXE & 0.32 & -0.18 & -0.81 & 0.13 \\
\hline S-PIXE & 0.03 & 0.11 & 0.20 & 0.93 \\
\hline Pb-PIXE & -0.49 & 0.35 & -0.29 & 0.68 \\
\hline$\%$ variance & 30 & 23 & 17 & 12 \\
\hline
\end{tabular}

Elements and fragments detected by ToF-SIMS in negative mode, tracers of some sources detected by PIXE (with this label) and OPT, have been considered. In the last row the percentage of variance associated to each factor. Factors loading greater than 0.6 are marked in bold character.

mode. Since ToF-SIMS can only measure relative trends [6] we created, for each sampling site, a normalized table including the data of the SIMS elements/fragments signals, the hourly values for OPT (deduced by optical analysis, see para 2) and the hourly concentration of some elements measured by PIXE. In addition, tracers of specific particulate matter sources were defined, e.g. in 2001 when the sampling took place, leaded gasoline was still quite commonly used in Italy and, therefore, following the results reported in [7], we chose the $\mathrm{Pb}$ data obtained by PIXE (Pb-PIXE) as a tracer for traffic (with the exception of the Milan data where Br-PIXE was preferred as traffic tracer since we revealed a significant contribution to $\mathrm{Pb}$ concentration from industrial sources). We used S-PIXE as a tracer for oil combustion and, in
Milan only, Mn-PIXE as tracer for industry. AlPIXE and Na-PIXE were assumed to be tracers of soil dust and sea-salt aerosol, respectively. The OPT variable has been included in the statistical analysis since for all four sampling sites it has shown a correlation with traffic [7].

The obtained data sets were both analysed by a varimax-rotated principal component analysis, PCA [15], and by cluster analysis using an Euclidean distance and a complete linkage algorithm [16], the latter being the same approach of a previous preliminary work [6]. In this work, where we exploit for the first time the combined use of PIXE and SIMS, we compare, as a cross-check, cluster analysis and PCA, being aware that the data set available for each sampling site (50 points) is relatively small. In PCA, only components with 
eigenvalue greater than 1 (before rotation) have been considered and, in all the cases, a percentage of global variance ranging from $76 \%$ to $88 \%$ has been accounted for. Both the methods (PCA and cluster analysis) produced the same overall picture with slightly fluctuations in their results, thus confirming their reliability.

The PCA results and the cluster plots including the ToF-SIMS data measured in positive mode gave a relatively poor information. The only molecular signals in this mode, $\mathrm{NH}_{3}^{+}$and $\mathrm{NH}_{4}^{+}$, group always together and show associations with other elements depending on the sampling site. For the data from Milan for instance, they got correlated with traffic tracers (e.g. $\mathrm{Br}$ and OPT). For Genoa and Naples the $\mathrm{NH}_{3}^{+}$and $\mathrm{NH}_{4}^{+}$signals were correlated with natural source tracers (e.g. $\mathrm{Na}$ and $\mathrm{Al}$ ), while within the Florence data they formed a separate group.

More information came from the analyses which included the ToF-SIMS data in negative mode. Table 2 (Panel A-Panel D) and Fig. 2(a)(d) show, respectively, the PCA results and the hierarchical cluster plots of the relevant negative fragments measured by ToF-SIMS, the data obtained by PIXE and OPT data. The comparison of the four sampling sites reveals significant differences. In Milan (Table 2, Panel C and Fig. 2(c)), $\mathrm{NO}_{x}$ molecules show a correlation with traffic tracers (OPT) but with Mn-PIXE too, considered a tracer of industrial activities, while all the $\mathrm{S}$ and $\mathrm{SO}_{x}$ compounds (with the exception of $\mathrm{NaSO}_{4}$ ) form a separate group. The picture of Naples (Table 2, Panel D and Fig. 2(d)) is somewhat different in that both $\mathrm{NO}_{x}$ and $\mathrm{SO}_{x}$ compounds tend to mix in 2-3 groups (Table 2, Panel D) and the traffic tracers (OPT, Pb-PIXE, partially Br-SIMS) form a separate group. The $\mathrm{SO}_{x}$ data on the other hand also appear in a group including $\mathrm{Na}$, which most probably refers to the influence of the sea. It should be noted that in Naples no significant tracer of industrial activities have been found [7]. In
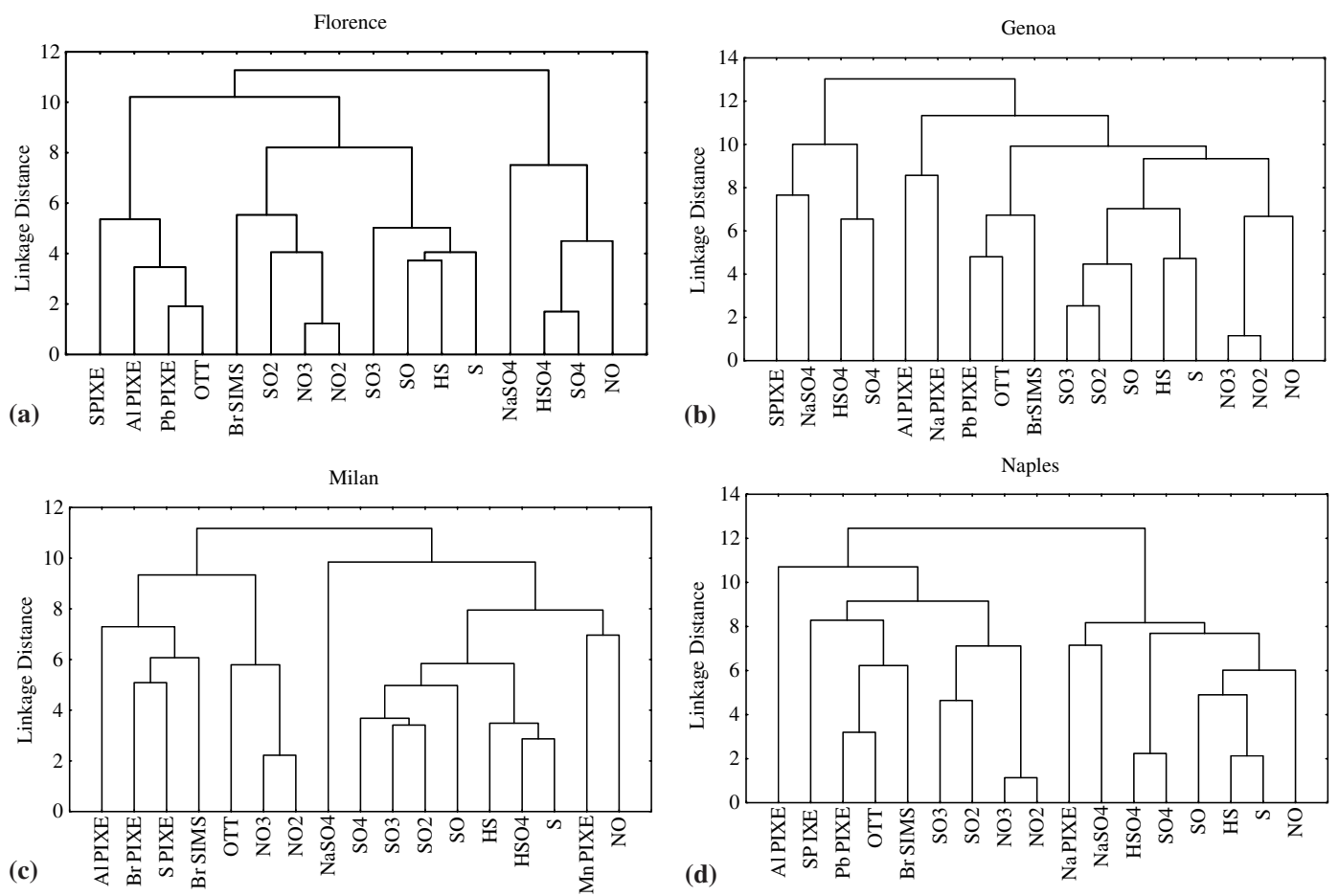

Fig. 2. Cluster analysis results on the data sets of Florence (a), Genoa (b), Milan (c) and Naples (d). Molecules detected by ToF-SIMS in negative mode, tracers of some sources detected by PIXE (with this label) and OPT, have been considered. 

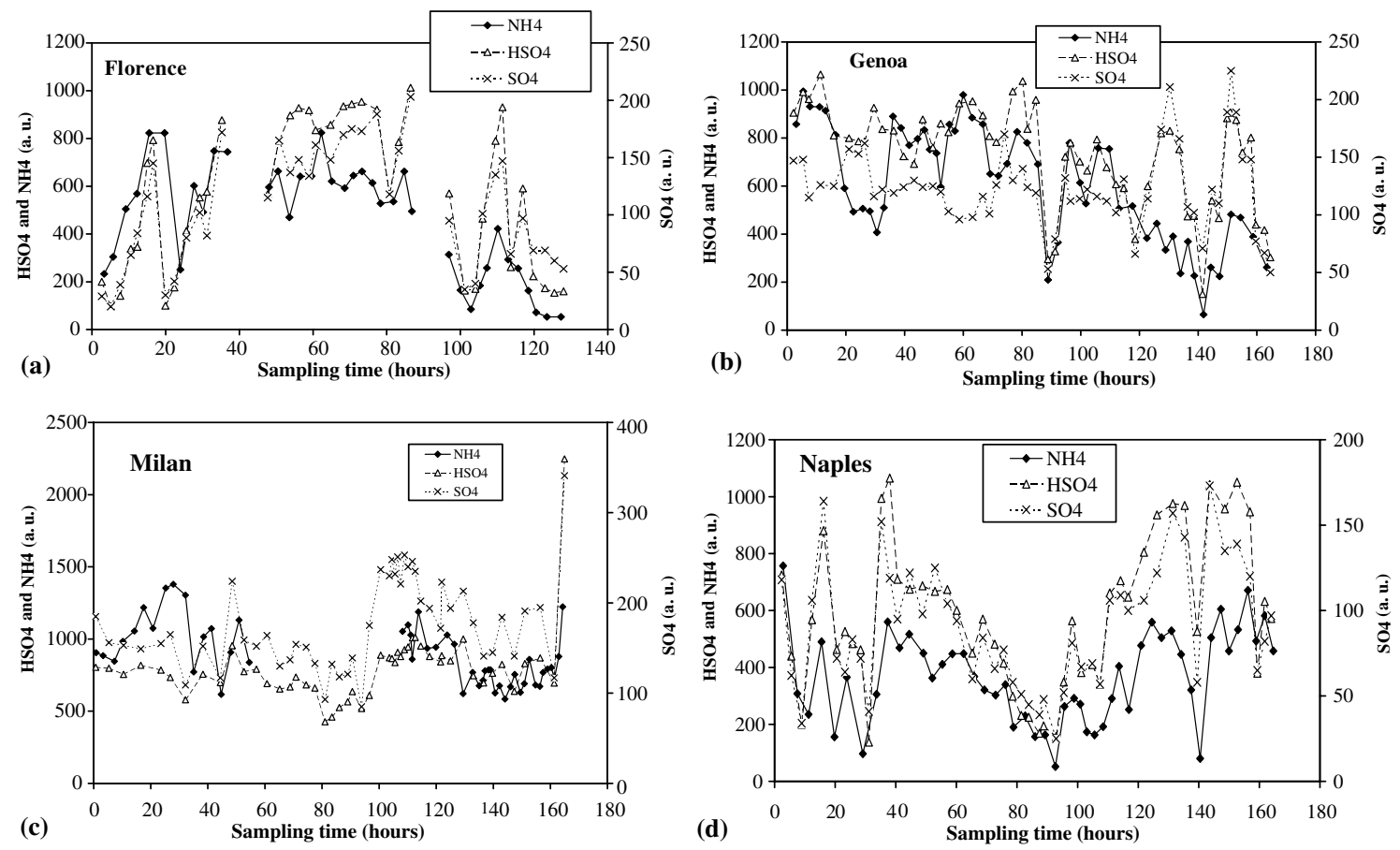

Fig. 3. Peak intensities time series measured by ToF-SIMS for the negative fragments $\mathrm{SO}_{4}$ and $\mathrm{HSO}_{4}$ and the positive fragment $\mathrm{NH}_{4}$ : (a) Florence, (b) Genoa, (c) Milan (d) Naples. Hour 0 marks the sampling start (January 17th, 2001, 11 a.m.).

Florence (Table 2, Panel A and Fig. 2(a)) we find again a cluster including $\mathrm{Br}, \mathrm{SO}_{2}, \mathrm{NO}_{2}$ and $\mathrm{NO}_{3}$ probably linked to traffic but not-correlated with any PIXE element. In this site, aggregation among $\mathrm{S}$ compounds similar to those described above can be noted again. Finally, in Genoa (Table 2, Panel $\mathrm{B}$ and Fig. 2(b)) a traffic cluster including $\mathrm{Pb}$ PIXE, OPT, Br-SIMS $\mathrm{NO}_{2}$ and $\mathrm{NO}_{3}$ can be observed (mainly by PCA, Table 2, Panel B). Sulphur compounds form one separate group, while SPIXE shows a correlation with Na-PIXE only. It should be noted that while the S-PIXE signal is proportional to the total number of $S$ atoms in the particulate matter, irrespective of their molecular state, S-SIMS is relative to atomic fragments only, easily produced by the breaking of HS molecules. Actually, molecules and/or fragments containing $\mathrm{S}$ are distributed by PCA (see Table 2) in several factors which show a variance of the same order of magnitude (see Table 2).

Basically, the picture emerging from cluster analysis and PCA completes with information on molecular fragments the results in [7] where traffic was indicated as the major particulate matters source in all the towns.

SIMS data measured in negative and positive mode cannot be merged in a unique data set since they do not exactly correspond to the same analysed points on the samples. However, time trends can be compared to single out possible correlations among molecules/fragments. In Fig. 3, time trends of $\mathrm{HSO}_{4}$ and $\mathrm{SO}_{4}$ (negative fragments) are compared with those of $\mathrm{NH}_{4}$ (positive fragments, nitrates tracer). These fragments show a clear correlation (in particular in Florence and Naples), suggesting a common origin from $\left(\mathrm{NH}_{4}\right)_{2} \mathrm{SO}_{4}$ or $\left(\mathrm{NH}_{4}\right) \mathrm{HSO}_{4}$ molecules.

\section{Conclusions}

A coordinated analysis on particulate matter samples collected with hourly resolution in four urban Italian sites has been conducted, exploiting 
the features of different IBA techniques. While PIXE is a well established powerful tool in aerosol studies, we have explored in this work the potential of a combined use of ToF-SIMS and PIXE for obtaining information of elements and molecular fragments not detectable by X-ray spectroscopy techniques.

The application of ToF-SIMS to aerosol samples clearly shows the presence of low $Z$ elemental ions $\left(\mathrm{Li}^{+}, \mathrm{B}^{+}, \mathrm{F}^{-}\right)$and of key ions as $\mathrm{NH}_{4}^{+}, \mathrm{NH}_{3}^{+}$, $\mathrm{SO}_{4}^{-}, \mathrm{SO}_{3}^{-}, \mathrm{NO}_{3}^{-}, \mathrm{NO}_{2}^{-}, \mathrm{HSO}_{4}^{-}, \mathrm{NaSO}_{4}$ and numerous Carbon organic molecule fragments. The similar time dependence of some molecule fragments identifies ammonium sulphate and ammonium nitrate in particulate matter and the occurrence of sodium nitrate and sulphate in samples collected at marine locations.

Despite the difficulty of obtaining concentration data by ToF-SIMS, time series of elements detected by both techniques showed similar trend. We therefore could merge all the data and compare the results of multivariate and cluster analysis for the four sampling sites. This work indicates that ToF-SIMS can play a role in aerosol studies as a complementary tool, in particular when samples collected by continuous samplers can be analysed with non-destructive approaches only. Nevertheless, improvements to speed up sample analysis and data reduction together with developments to obtain more quantitative information (i.e. concentration values) are still necessary to consider ToF-SIMS as a completely asserted tool for aerosol studies.

\section{Acknowledgements}

We thank the local authorities of Florence, Genoa, Milan and Naples for the permission to use structures and data, and for their valuable assistance during the sampling campaign. We are in- debted to Prof. Renata Moro and Dr. Luigi Campajola for their help in organizing the Naples sampling. A particular thanks to the staff of the Department of Chemistry, University of Antwerp for the kind assistance during the ToF-SIMS measurements.

\section{References}

[1] S.A.E. Johansson, J.L. Campbell, K.J. Malmquvists, Particle-Induced X-Ray Emission Spectroscopy, John Wiley \& Sons, Chichester, 1995.

[2] C. Boni, A. Caridi, E. Cereda, G.M.B. Marcazzan, Nucl. Instr. and Meth. B 47 (1990) 133.

[3] J.A. Leavitt, L.C. McIntyre Jr., M.R. Weller, Backscattering Spectrometry in Handbook of Modern Ion Beam Materials Analysis, MRS, Pittsburgh, 1995.

[4] H.J. Annegarn, T.A. Cahill, J.F.P. Sellschop, A. Zucchiatti, Phys. Scr. 37 (1998) 282.

[5] P. Prati, A. Zucchiatti, F. Lucarelli, P.A. Mandò, Atmos. Environ. 34 (2000) 3149.

[6] R. Van Ham, A. Adriaens, P. Prati, A. Zucchiatti, L. Van Vaeck, F. Adams, Atmos. Environ. 36 (5) (2002) 899.

[7] A. D'Alessandro, F. Lucarelli, P.A. Mandò, G. Marcazzan, S. Nava, P. Prati, G. Valli, R. Vecchi, A. Zucchiatti, J. Aerosol Sci. 34 (2003) 243.

[8] E. Filippi, P. Prati, A. Zucchiatti, F. Lucarelli, P.A. Mandò, V. Ariola, P. Corvisiero, Nucl. Instr. and Meth. B 150 (1999) 370.

[9] P. Formenti, P. Prati, A. Zucchiatti, F. Lucarelli, P.A. Mandò, Nucl. Instr. and Meth. B 113 (1996) 359.

[10] J.D. Lindberg, R.E. Douglass, D.M. Garvey, Appl. Opt. 38 (12) (1999) 2369.

[11] H. Horvath, Atmos. Environ. 27A (3) (1993) 293.

[12] P. Del Carmine, F. Lucarelli, P.A. Mandò, G. Moscheni, A. Pecchioli, D.J. MacArthur, Nucl. Instr. and Meth. B 45 (1990) 341.

[13] J.A. Maxwell, W.J. Teesdale, J.L. Campbell, Nucl. Instr. and Meth. B 95 (1995) 407.

[14] A. Adriaens, R. Van Ham, L. Van Vaeck, in: J.C. Vickerman, D. Briggs (Eds.), TOF SIMS: Surface Analysis by Mass Spectrometer, Surface Spectra and IM Publication, West Sassex, UK, 2001.

[15] N.Z. Heidam, Atmos. Environ. 16 (8) (1982) 1923.

[16] Statgraphics plus@ Copyright 1995, Manugistic Inc., Rockville, MD, USA. 